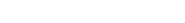

\title{
Importance of Taguchi's Method in Optimization of Various Problems in Service Sector
}

\author{
Ajay Mishra* \\ Department of Mechanical Engineering, Oriental University, Indore, India \\ *Corresponding author: Mishra A, Department of Mechanical Engineering, Oriental University, Indore, India, Tel: +91 9827434208; E-mail: \\ ajay_mishra552000@rediffmail.com
}

Received date: Dec 05, 2015; Accepted date: Dec 07, 2015; Published date: Dec 09, 2015

Copyright: $\odot 2015$ Mishra A. This is an open-access article distributed under the terms of the Creative Commons Attribution License, which permits unrestricted use, distribution, and reproduction in any medium, provided the original author and source are credited.

\section{Introduction}

Taguchi's parameter design approach offers a step by step methodology for optimization of various parameters with regard to performance, quality and cost [1]. The quality of design may be enhanced by enhancing the quality and productivity in different organization-wide performances. Those performances concerned with quality incorporate in quality of product planning, product design and process design [2]. During the decades after the introduction of Taguchi's method it was applied in diverse industries specially in manufacturing and production industries. Despite numerous applications of the technique in industrial processes, it was rarely used in service processes.

The use of Taguchi methodology of robust design in service industry was first made by M.C. Holcomb in 1994. Here, Taguchi methodology was applied in the designing of logistic services with the help of Taguchi's inner and outer orthogonal arrays and signal to noise ratios $(\mathrm{S} / \mathrm{N})$.

Morsi et al. [3] applied Taguchi's method for the concurrent evaluation of the impact of multiple factors in the tumour microenvironment. The objective of this paper was to assess the ability of Taguchi methodology to study the impact of number of factors simultaneously on the death or survival of the malignant cells. A main contribution of this paper was that the Taguchi method estimated the different factors combination which were result in the lowest survival of malignant cells.

Taner et al. [4] establishes the critical score and screening accuracy of the CAGE questionnaire in the three treatment settings, primary health care, walk-in clinic and the emergency room. Taguchi's robust design techniques were used in the three screens of the CAGE questionnaire with sensitivity and specificity analysis. This paper suggests that, to reduce the misclassification rates of alcohol abuse, screening system should concentrate first on developing ways to standardize protocols.

Taner et al. [5] presented a study to show how Taguchi method can be used in the medical industry. In this paper, the loss function developed by Taguchi was integrated with the performance and parameters of the design of medical applications. This paper shows that when the patient requirements are continuously met then minimal losses will increase the patient satisfaction. This paper outlines the areas in the health care industry where Taguchi's method can be easily applied.

Taner et al. [6] show how to successfully apply Taguchi's method in health care industry to increase the quality of medical images. This paper shows that the performance of any imaging equipment may be measured by $\mathrm{S} / \mathrm{N}$. They collected the data from a database of 82 diagnostic thoracic computed tomography (CT) scans and $\mathrm{S} / \mathrm{N}$ ratios were calculated. With the help of Taguchi's method, robust and reliable medical systems were designed at the same time avoiding the observer biasness.

Ordoobadi [7] provide a tool for decision makers to consider both tangible and intangible factors while making decision regarding the investments in advanced manufacturing technologies (AMT). This study shows the application of loss function developed by Taguchi to quantify the intangible benefits. The propose procedure helps companies to rank the technology alternatives and lastly to identify the best technology to be adopted.

Ordoobadi [8] again presented a tool for managers for making more informed outsourcing decision regarding the selection of suppliers. This method uses the loss function developed by the Taguchi for the inclusion of intangibles in evaluation and selection of suppliers. To achieve a single measure during the study, different weighted loss scores are combined to determine single weighted score for each of the supplier. The supplier who receives the minimum loss score will be finally selected.

Bayumi et al. [9] uses L16 orthogonal array for five control parameters which are font size, font style, line spacing, text/ background colour combination and viewing distance with four levels of each and the other variables like table height, inclination angle and illumination were fixed. The researchers obtained the number of words read by each subject in a ten minute time period from which the number of words read per minute is computed; thereafter analysis is conducted to find the optimum levels. Based on experimental data, analysis of variance was undertaken which determines the process parameters most contributing to the optimal level. The percentage contribution of the font size is $6.15 \%$; font style is $37.44 \%$; line spacing is $19.54 \%$; text/background colour combination is $18.08 \%$; and viewing distance is $7.70 \%$. The maximum contribution is of font style for obtaining the maximum value of the number of words read per minute.

Mishra et al. [10] conducted an empirical analysis is based on data obtained from consumer survey and data were analyzed using Taguchi method and ANOVA. This study introduces the concept of Taguchi's method of optimization in analysis and quantification of factors affecting the success of retail outlets. In 2015, they applied [11] Taguchi's method of optimization in optimizing the VDU parameters setting for maximizing the readability on laptop.

Over the last few decades, the service sector has become the dominant contributor in the economies of various countries and it accounted for more than $50 \%$ of Gross Domestic Product (GDP). At the same time, the knowledge generated from Taguchi's optimization 
Citation: Mishra A (2015) Importance of Taguchi's Method in Optimization of Various Problems in Service Sector. Ind Eng Manage 4: e131. doi: $10.4172 / 2169-0316.1000 \mathrm{e} 131$

Page 2 of 2

technique over the last two decades has now become mature. So, the researchers from the optimization fields should come forward to apply Taguchi's technique for the improvement of various parameters in service sector also.

\section{References}

1. Phadke MS (1989) Quality Engineering Using Robust design, Prentice Hall, Eaglewood Cliffs, New Jersey.

2. Park SH (1997) Robust Design and Analysis for Quality Engineering. Quality and Reliability Engineering International 13-174.

3. Morsi H, Yong KL, Jewell AP (2004) Evaluation of the Taguchi methods for the simultaneous assessment of the effects of multiple variables in the tumour microenvironment. International seminars on Surgical Oncology.

4. Taner T, Antony J (2005) Determining positivity of alcohol abuse by Tagcuhi methods. International Journal of health care quality assurance 18 : 83-91.

5. Taner T, Antony J (2006) Applying Taguchi methods to the health care. Leadership in health services 19: 26-35.
6. Taner MT, Sezen B (2007) Taguchi's experimental design method on improvement of medical image quality. Leadership in health services 20: $42-51$.

7. Ordoobadi S (2009) Evaluation of advanced manufacturing technologies using Taguchi's loss functions. Journal of manufacturing technology management 20: 367-384.

8. Ordoobadi S (2009) Application of Taguchi loss functions for supplier selection. Supply chain management: An international Journal 14: 22-30.

9. Bayumi A, Shewakh WM, Haleem A (2013) Design optimal VDU parameters for the readability task to alleviate posture discomfort mental stressors. International Journal of Industrial engineering and technology 3 : 53-66.

10. Mishra A, Gangele A (2013) Application of Taguchi's Method of Optimization in analysis and quantification of factors affecting the success of retail outlets. International Journal of Engineering, Business and enterprise Applications, United States 1: 30-35.

11. Gangele A, Mishra A (2015) Optimal laptop VDU parameter setting using Taguchi method. Management Science Letters, Growing Science 5: 961-968. 